\title{
Optimasi Prediksi Nilai Tukar Rupiah Terhadap Dolar Menggunakan Neural Network Berbasiskan Algoritma Genetika
}

\author{
Primandani Arsi ${ }^{1}$, Joko Prayogi ${ }^{2}$ \\ 1,2Program Studi Informatika, Universitas Amikom Purwokerto \\ e-mail: 1ukhti.prima@amikompurwokerto.ac.id, 2joko.prayogi@gmail.com
}

\begin{abstract}
Abstrak
Nilai tukar adalah nilai mata uang sebuah negara yang dinyatakan dalam nilai mata uang negara lain. Sebagai contoh, nilai tukar rupiah (Rp) pada dolar amerika serikat (USD) adalah nilai satu dolar amerika dalam rupiah, begitu juga sebaliknya nilai satu rupiah terhadap dolar amerika. Korelasi nilai tukar ini kaitannya dengan pergadangan internasional dimana etidakpastian nilai tukar menjadi permasalahan yang penting dalam bidang keuangan. Oleh karena itu diperlukan sebuah model prediksi guna memprakirakan nilai tukar dimasa depan. Hasil yang akurat dalam prediksi nilai tukar ini sangat bermanfaat bagi pemegang kepentingan dimasa depan. Pada peneltian ini prediksi data nilai tukar rupiah pada dolar dilakukan dengan menggunakan Neural Network berbasis algoritma genetika. Berdasarkan eksperimen yang dilakukan pada data time series nilai tukar rupiah pada dolar periode 1 Januari 2013 sd 30 Agustus 2018 yang berjumlah 1470 record menggunakan metode Neural Network berbasis algoritma Genetika, terbukti bahwa model optimasi tersebut mampu meningkatkan hasil akurasi prediksi yaitu dari $0,010+/-0,001$ menjadi $0,008+/-0,001$, terjadi penurunan nilai RMSE sebesar 0,002 yang berarti peningkatan akurasi prediksi.
\end{abstract}

Kata kunci: Neural Network, algoritma genetika, nilai tukar rupiah, RMSE.

\begin{abstract}
The exchange rate is value or price of a country's currency measured or expressed in another country's currency. For example the exchange rate of the rupiah $(R p)$ to the United States dollar (USD) is the value of one US dollar in rupiah. The exchange rate correlation with international trade, it is very important that exchange rate uncertainty becomes an important issue in the financial sector. Therefore needed a prediction model to predict exchange rates in the future. Accurate results in exchange rate predictions are very beneficial for stakeholders in the future. In this study, the prediction of the rupiah exchange rate against the dollar using the Neural Network algorithm based on genetic algorithms. Based on experiments on time series data the exchange rate of the rupiah against the dollar in the period January 1, 2013 to August 30, 2018 with a totaly 1470 records using Neural Networks based on Genetic algorithms, prove that the model is able to improve the results of prediction accuracy results from $0.010+/-0.001$ to $0.008+/-0.001$. RMSE decreased by 0.002 that means an increase in prediction accuracy.
\end{abstract}

Keywords: Neural Network, genetic algorithm, rupiah exchange rate, RMSE.

\section{Pendahuluan}

Nilai tukar adalah nilai mata uang sebuah negara yang dinyatakan dalam mata uang negara lain(Junaidi, Sulasmiyati, \& Nurlaily, 2018). Contohnya nilai tukar rupiah (Rp) pada dolar amerika serikat (USD) adalah nilai satu dolar amerika dalam rupiah, begitu juga sebaliknya nilai satu rupiah pada dolar amerika. Korelasi nilai tukar ini kaitannya dengan pergadangan internasional (Shu, Shi, \& Ye, 2018). Dimana banyak negara yang terlibat dengan negara lain guna kepentingan ekspor dan impor barang namun membutuhkan sistim pembayaran yang sah(Caballero, Candelaria, \& Hael, 2018). Perbedaan nilai tukar ini merupakan salah satu hambatan 
dalam kegiatan ekspor dan impor(KallahiKarai \& Safari, 2018).

Saat ini mata uang terbitan Amerika Serikat (AS), menjadi mata uang terbanyak yang digunakan pada transaksi perdagangan dunia internassional. Dolar AS juga telah menjadi sarana cadangan devisa terpopuler di banyak negara, selain emas dan auro. Dimana dalam pasar valuta asing lebih dari $85 \%$ melibatkan dolar. Selain itu hutang yang ada didunia sebanyak 39\% diterbitkan dalam bentuk dolar(Lee, 2017).

Pergerakan pada nilai tukar rupiah menjadi trending topik yang ramai diperbincangkan sekarang ini(Demian \& Mauro, 2017). Meskipun pertumbuhan bisnis di Indonesia semakin meningkat, namun hal ini belum dapat membantu perekonomian semakin membaik salah satu penyebabnya dikarenakan nilai tukar rupiah pada dolar yang melemah. Data pada bank indonesia menunjukan bahwa nilai tukar rupiah pada dolar terus berubah-ubah bahkan cenderung mengalami pelemahan setiap tahun (Arifin \& Mayasya, 2018).

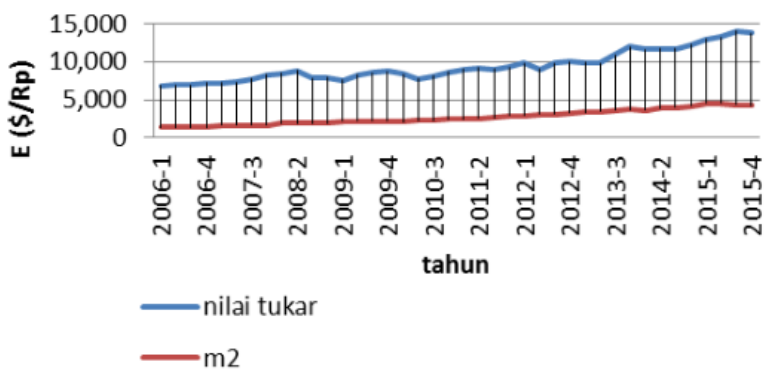

Gambar 1. Pelemahan nilai tukar

Adapun fluktuasi nilai tukar rupiah pada dolar ini sangat berpengaruh terhadap kebijakan moneter (Prasetyoningsih, Taunay, \& Fathoni, 2018). Dampak nyata dari fluktuasi tersebut juga berpengaruh pada harga barang, upah kerja, suku bunga dan jumlah pengangguran suatu negara (Pandey, Jagadev, Dehuri, \& Cho, 2018). Bagi pelaku bisnis ketidakpastian nilai tukar rupiah menimbulkan permasalahan yang berdampak kerugian pada usahanya (Mamadli, 2017). Sebagai contoh pada bisnis jual beli saham trader mengalami kesulitan dalam menentukan posisi buy, hold ataupun sell (Keefe \& Shadmanicor, 2018).

Ketidakpastian nilai tukar ini merupakan permasalahan yang penting dalam bidang keuangan(Shen, Chao, \& Zhao, 2015). Oleh karena itu diperlukan sebuah model prediksi guna memprakirakan nilai tukar dimasa depan. Hasil yang akurat dalam prediksi nilai tukar ini sangat bermanfaat bagi pemegang kepentingan dimasa yang akan datang(Thinyane \& Millin, 2011). Penelitian terkait prediksi dari nilai tukar rupiah telah dilakukan sebelumnya oleh Adani Dharmawati dengan menggunakan data nilai tukar rupiah terhadap mata uang euro menggunakan algoritma penggabungan neural network dengan particle swarm optimization (Dharmawati, 2018). Data time series nilai tukar USD/CAD, USD/CHF dan USD/JPY juga digunakan dalam penelitian Rajashree Dash pada prediksinya yang berbasiskan Neural Network (Dash, 2018). Penelitian selanjutnya dilakukan oleh Castaka Agus S dan Faishal $F$ dimana data pergerakan harga valas diprediksi menggunakan algoritma Neural Network(Sugianto \& Fachruddin, 2018)

Algoritma Neural Network teruji kehandalannya dalam prediksi bidang keuangan seperti prediksi penjualan, prediksi pergerakan saham dan prediksi nilai tukar (Moghaddam et al., 2016). Namun Neural Network memiliki kelemahan yaitu lambatnya laju konvergensi serta sering terjebak pada minimum lokal sehingga menyebabkan sebuah kegagalan pada proses pencarian solusi yang maksimal untuk penentuan fitur dalam bobot atribut yang dipakai(Nikentari, Kurniawan, Ritha, \& Kurniawan, 2018). Hal ini dapat diatasi dengan menggunakan algoritma optimasi. Terdapat beberapa algoritma optimasi salah satunya adalah algoritma genetika. Algoritma genetika adalah algoritma yang tepat dalam penyelesaian permasalahan terkait optimasi kompleks dimana metode konvensional tidak mampu menyelesaikan(Wicaksono, 2019).

Pada percobaan yang dilakukan oleh Mohammad Badrul (2017) penerapan algoritma genetika pada Neural Network dilakukan guna meningkatkan akurasi prediksi pada data pemilukada(Badrul, 2017). Selain itu pada prediksi curah hujan di daerah batu yang dilakukan oleh Ida Wahyuni dkk (2018), dimana algoritma genetika diterapkan pada FIS Tsukamoto terbukti mempengaruhi tingkat akurasai prediksi menjadi lebih baik(Wahyuni, Ahda, \& Adipraja, 2018). 
Oleh sebab itu dari percobaan yang telah dilakukan oleh penulis sebelumnya (Arsi, Somantri, Hasanah, Imron, \& Waluyo, 2018) dimana prediksi data nilai tukar rupiah pada dolar dilakukan dengan menggunakan algoritma Neural Network, penulis mengusulkan penerapan algoritma optimasi genetika untuk mengoptimasi hasil prediksi nilai tukar mata uang rupiah. Hasil prediksi dengan penerapan metode yang tepat dilihat dengan hasil nilai error atau kesalahan yang paling minimum. Semakin kecil error yang dihasilkan semakin baik ketepatan prediksinya(Windarti \& Sulistyowati, 2019).

\section{Metode Penelitian \\ 1. Dataset}

Pada penelitian ini digunakan data time series yang bersifat publik dari website resmi Bank Indonesia, yakni data nilai tukar mata uang rupiah pada dolar amerika serikat kurun waktu 5 tahun ( 1 januari 2013 sd 30 Agustus 2018) berjumlah 1470 record. Dengan jumlah atribut 4 buah, yakni nilai, kurs jual, kurs beli dan tanggal. Tampak dalam tabel 1 berikut.

Tabel 1.Data real nilai tukar rupiah pada dolar

\begin{tabular}{|l|l|l|l|l|}
\hline No. & Nilai & Kurs Jual & Kurs Beli & Tanggal \\
\hline 1 & 1,00 & $14.785,00$ & $14.637,00$ & $31 / 8 / 18$ \\
\hline 2 & 1,00 & $14.728,00$ & $14.582,00$ & $30 / 8 / 18$ \\
\hline 3 & 1,00 & $14.716,00$ & $14.570,00$ & $29 / 8 / 18$ \\
\hline 4 & 1,00 & $14.687,00$ & $14.541,00$ & $28 / 8 / 18$ \\
\hline 5 & 1,00 & $14.683,00$ & $14.537,00$ & $27 / 8 / 18$ \\
\hline$\ldots$ & $\ldots$ & $\ldots$ & $\ldots$ & $\ldots$ \\
\hline$\ldots$ & $\ldots$ & $\ldots$ & $\ldots$ & $\ldots$ \\
\hline 1466 & 1,00 & $9.789,00$ & $9.691,00$ & $8 / 1 / 13$ \\
\hline 1467 & 1,00 & $9.787,00$ & $9.689,00$ & $7 / 1 / 13$ \\
\hline 1468 & 1,00 & $9.723,00$ & $9.627,00$ & $4 / 1 / 13$ \\
\hline 1469 & 1,00 & $9.718,00$ & $9.622,00$ & $3 / 1 / 13$ \\
\hline 1470 & 1,00 & $9.733,00$ & $9.637,00$ & $2 / 1 / 13$ \\
\hline
\end{tabular}

\section{Preprocessing}

Tahapan pengolahan data awal dibagi menjadi 2. Tahapan yang pertama adalah seleksi atribut. Pada tahapan ini atribut yang tidak terpakai dihilangkan yakni nilai dan kurs beli. Sehingga didapatkan variabel seperti yang terlihat pada tabel dibawah ini.
Tabel 2. Variabel yang digunakan

\begin{tabular}{|c|c|}
\hline Kurs & Tanggal \\
\hline $14.785,00$ & 31 Agust 2018 \\
\hline $14.728,00$ & 30 Agust 2018 \\
\hline $14.716,00$ & 29 Agust 2018 \\
\hline $14.687,00$ & 28 Agust 2018 \\
\hline $14.683,00$ & 27 Agust 2018 \\
\hline $14.728,00$ & 24 Agust 2018 \\
\hline$\ldots$ & $\ldots$ \\
\hline$\ldots$ & $\ldots$ \\
\hline $9.789,00$ & 8 Jan 2013 \\
\hline $9.787,00$ & 7 Jan 2013 \\
\hline $9.723,00$ & 4 Jan 2013 \\
\hline $9.718,00$ & 3 Jan 2013 \\
\hline $9.733,00$ & 2 Jan 2013 \\
\hline
\end{tabular}

Selanjutnya data yang telah melalui tahap seleksi atribut ini kemudian dinormalisasi dengan tujuan untuk meminimalkan redundasi agar data tersebut dapat bekerja secara optimal(Jain, Shukla, \& Wadhvani, 2018). Normalisasi data dilakukan dengan skala 0 sd 1 (Christioko, Indriyawati, \& Hidayati, 2017)). Tahap selanjutnya yakni pemilihan variabel yang digunakan sebagai input dan output. Guna menentukan variabel input diterapkan teknik windowing yaitu proses dimana data time series dirubah menjadi sample set dengan beberapa atribut yang diinginkan (Steinwandter, Šišmiš, Sagmeister, Bodenhofer, \& Herwig, 2018). Pada penelitian ini penulis menetapkan window size 10 (Dash, 2018).

\section{Metode yang diusulkan}

Model yang dibangun untuk memprediksi nilai tukar rupiah pada dolar yaitu dengan menggunakan model Neural Network yang di implementasikan pada algoritma Genetika guna optimasi hasil prediksi dari metode Neural Network. Pencarian nilai parameter Neural Network berupa Momentum dan Learning Rate dilakukan oleh Algoritma Genetika. Algoritma Genetika melakukan teknik pencarian parameter didasarkan pada proses mekanisme seleksi dan genetika ilmiah(Suryani \& Priyanti, 2019). Sehingga akurasi menjadi lebih tepat dan optimal. Ketepaan ukuran jaringan Neural Network berpengaruh pada konvergensi serta kualitas hasil prediksi (Jena, Majhi, \& Majhi, 2015).

$\begin{array}{ccc}\text { Sebelum } & \text { mengimplementasikan } \\ \text { Neural Network terhadap Algoritma }\end{array}$ 
Genetika, dilakukan eksperimen terhadap parameter Neural Network secara manual untuk mencari parameter terbaik yakni parameter training cycles, momentum dan learning rate. Kinerja dari kombinasi ketiga parameter tersebut kemudian diukur menggunakan Root Mean Square Eror (RMSE). Semakin kecil nilai dari RMSE yang dihasilkan maka sebakin baik hasil akurasi prediksi yang dihasilkan. Hasil Prediksi model Neural Network selanjutnya dibandingkan dengan hasil prediksi Neural Network + Algoritma Genetika. Adapun tools yang digunakan adalah RapidminerStudio 9.0 .

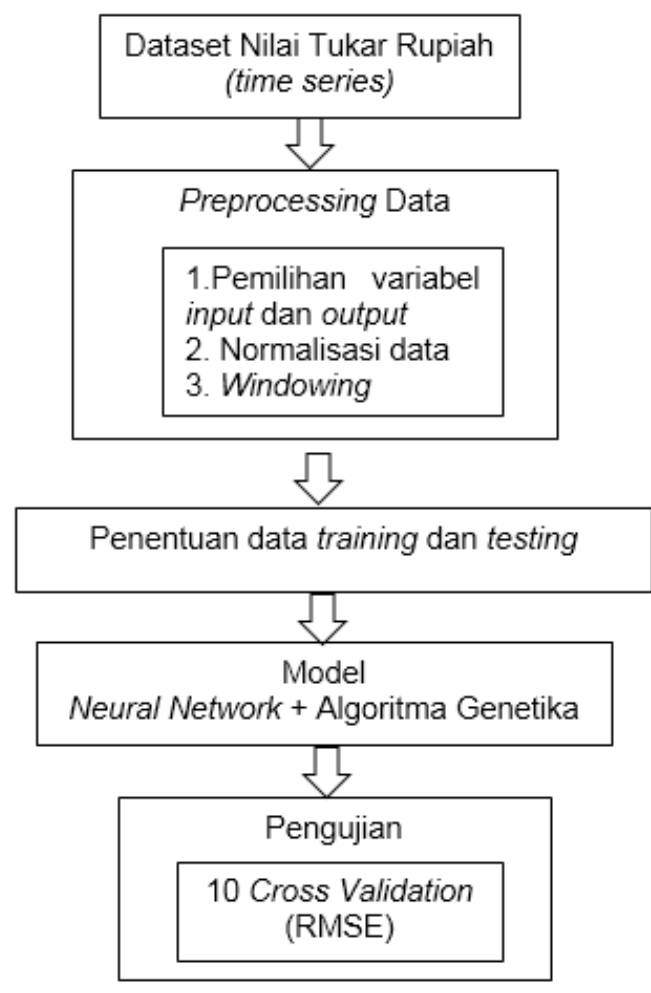

Gambar 2. Metode yang diusulkan

\section{Evaluasi dan Validasi}

Guna melihat tingkat akurasi hasil prediksi yang dihasilkan digunakan model validasi Cross $k$-Fold Validation dengan $k=10$. Selanjutnya evaluasi dilakukan dengan cara membadingkan model dari Neural Network dengan Neural Network berbasis Algoritma Genetika.

\section{Hasil dan Pembahasan \\ 1. Model Neural Network}

Dari hasil uji coba terhadap ketiga parameter Neural Network yakni training cycles, learning rate dan momentum didapatkan hasil RMSE terbaik yakni 0.010 +/- 0.001. Dengan arsitektur Neural Network seperti yang terlihat pada Gbr 3 .

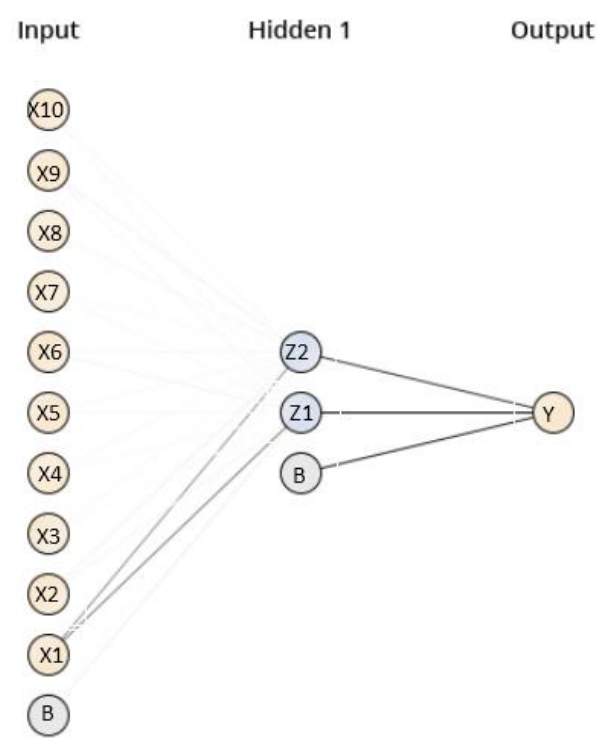

Gambar 3. Arsitektur Neural Network terbaik

Jumlah neuron pada input terdiri dari 10 neuron, hidden layer sejumlah 1 layer dengan jumlah neuron sebanyak 2 neuron serta 1 neuron sebagai output. Sebagaimana yang terlihat pada Gambar 2. Parameter terbaik yang digunakan untuk memprediksi nilai tukar mata uang rupiah ditampilkan pada tabel 3 berikut.

Tabel 3. Kombinasi parameter terbaik Neural Network

\begin{tabular}{|c|c|}
\hline Input (neuron) & 10 \\
\hline Output (neuron) & 1 \\
\hline Training cycles & 300 \\
\hline $\begin{array}{l}\text { Hidden Layer / } \\
\text { neuron }\end{array}$ & $1 / 2$ \\
\hline Learning rate & 0,01 \\
\hline Momentum & 0,9 \\
\hline RMSE & $0,010+/-0,001$ \\
\hline
\end{tabular}

2. Model Neural Network yang berbasiskan Algoritma Genetika

Pada tahap ini Algoritma Genetika diterapkan pada Neural Network untuk pencarian nilai parameter learning rate dan momentum terbaik dengan penentuan parameter algoritma Genetika seperti yang terlihat pada tabel 4 dibawah ini. 
JURNAL INFORMATIKA, Vol.7 No.1 April 2020

ISSN: 2355-6579 | E-ISSN: 2528-2247

Tabel 4. Parameter Algoritma Genetika

\begin{tabular}{|l|l|}
\hline Max generatiom & 10 \\
\hline Population size & 40 \\
\hline Mutation type & Gaussian mutation \\
\hline Selection type & Roulette wheel \\
\hline Crossover prob & 0,5 \\
\hline RMSE & $\mathbf{0 . 0 0 8 + / - 0 . 0 0 1}$ \\
\hline
\end{tabular}

Parameter algoritma Genetika yang digunakan untuk pencarian parameter Neural Network terbaik yakni Max generation $=10$, population size $=40$, Mutation type $=$ Gaussian mutation, Selection type $=$ Roulette wheel, Crossover prob $=0,5$. Sehingga menghasilkan RMSE 0,008 +/0,001

\section{Pengujian dan perbandingan model}

Setelah dilakukan eksperimen terhadap model Neural Network dan Neural Network yang di optimasi algoritma Genetika, maka didapatkan hasil prediksi seperti yang terlihat pada tabel 5 berikut.

Tabel 5. Perbandingan hasil predikksi Neural Network dengan Neural Network + GA

\begin{tabular}{|l|l|ll|}
\hline Parameter & \multicolumn{1}{|c|}{$\begin{array}{c}\text { Neural } \\
\text { Network }\end{array}$} & $\begin{array}{c}\text { Neural } \\
\text { Network + GA }\end{array}$ \\
\hline $\begin{array}{l}\text { Learning } \\
\text { rate }\end{array}$ & 0,01 & $\begin{array}{l}0,0104844865 \\
43244\end{array}$ \\
\hline Momentum & 0,9 & $\begin{array}{l}0,8633563476 \\
940593\end{array}$ \\
\hline RMSE & $\mathbf{0 , 0 1 0 \quad + / -}$ & $\mathbf{0 , 0 0 8} \quad+/-$ \\
& $\mathbf{0 , 0 0 1}$ & $\mathbf{0 , 0 0 1}$ & \\
\hline
\end{tabular}

Analisa dari eksperimen yang telah dilakukan menunjukan bahwa dengan adanya optimasi penentuan parameter Neural Network menggunakan Algoritma Genetika menjadikan akurasi prediksi menjadi lebih baik, yakni dari nilai RMSE $0,010+/-0,001$ menjadi 0,008 +/- 0,001. Terjadi penurunan nilai RMSE sebesar 0,002 yang berarti Neural Network yang di optimasi dengan Algoritma Genetika lebih baik dibandingkan Neural Network tanpa algoritma Genetika.

\section{Kesimpulan}

Berdasarkan eksperimen yang dilakukan pada data time series nilai tukar rupiah terhadap dolar periode 1 Januari 2013 sd 30 Agustus 2018 yang berjumlah 1470 record menggunakan Neural Network kombinasi algoritma Genetika, terbukti bahwa model optimasi tersebut mampu meningkatkan hasil akurasi prediksi yaitu dari 0,010+/-0,001 menjadi 0,008 +/-0,001, terjadi penurunan nilai RMSE sebesar 0,002 yang berarti peningkatan akurasi prediksi. Dengan adanya model optimasi prediksi ini diharapkan dapat diimplementasikan menjadi sebuah aplikasi yang dapat digunakan investor terkait prediksi nilai tukar rupiah. Selanjutnya guna kelanjutan dari penelitian ini diperlukan lebih banyak atribut yang dapat mempengaruhi nilai tukar rupiah pada dolar dengan solusi penyeleksian atribut menggunakan feature selection.

\section{Referensi}

Arifin, S., \& Mayasya, S. (2018). Faktor faktor yang mempengaruhi nilai tukar rupiah terhadap dolar amerika serikat. Jurnal Ekonomi-Qu, 8(1), 82-96.

Arsi, P., Somantri, O., Hasanah, U., Imron, M., \& Waluyo, R. (2018). A Proposed Model Of Neural Network For Rupiah Exchange Rate's Prediction (pp. 2-5). IEEE.

Badrul, M. (2017). Optimasi Algoritma Neural Network Dengan Algoritma Genetika Dan Particle Swarm Optimization Untuk Memprediksi Hasil Pemilukada. Jurnal Pilar Nusa Mandiri, 13(1), 1-11. Retrieved from http://ejournal.nusamandiri.ac.id/ejurn al/index.php/pilar/article/view/329

Caballero, J., Candelaria, C., \& Hael, G. (2018). Bank linkages and international trade. Journal of International Economics, 115, 30-47. https://doi.org/10.1016/j.jinteco.2018.0 8.006

Christioko, B. V., Indriyawati, H., \& Hidayati, N. (2017). Fuzzy Multi-Atribute Decision Making ( Fuzzy Madm ) Dengan Metode Saw Untuk Pemilihan Mahasiswa Berprestasi. Jurnal Transformatika, 14(2), 82-85.

Dash, R. (2018). Performance analysis of a higher order neural network with an improved shuffled frog leaping algorithm for currency exchange rate prediction. Applied Soft Computing Journal, 67, 215-231. https://doi.org/10.1016/j.asoc.2018.02. 043

Demian, C.-V., \& Mauro, F. Di. (2017). The exchange rate, asymmetric shocks and asymmetric distributions. International 
Economics, $\quad 154, \quad 68-85$. https://doi.org/10.1016/j.inteco.2017.1 0.005

Dharmawati, A. (2018). Model Neural Network Berbasis Pso Dalam Prediksi Nilai Tukar Rupiah Terhadap Euro. Technologia, 9(1), 26-32.

Jain, S., Shukla, S., \& Wadhvani, R. (2018). Dynamic selection of Normalization Techniques using Data Complexity Measures. Expert Systems with Applications, 106, 252-262. https://doi.org/10.1016/j.eswa.2018.04 .008

Jena, P. R., Majhi, R., \& Majhi, B. (2015). Development and performance evaluation of a novel knowledge guided artificial neural network (KGANN) model for exchange rate prediction. Journal of King Saud University - Computer and Information Sciences, 27(4), 450-457. https://doi.org/10.1016/j.jksuci.2015.0 1.002

Junaidi, S. K., Sulasmiyati, S., \& Nurlaily, F. (2018). Pengaruh Pendapatan Nasional, Inflasi Dan Nilai Tukar Yuan Terhadap Impor Indonesia Dari China Periode 2010-2017. Jurnal Administrasi Bisnis (JAB), 60(2), 111118.

Kallahi-Karai, K., \& Safari, P. (2018). Future exchange rates and Siegel's paradox. Global Finance Journal, 37, 168-172. https://doi.org/10.1016/j.gfj.2018.04.00 7

Keefe, H. G., \& Shadmanicor, H. (2018). Foreign exchange market intervention and asymmetric preferences. Emerging Markets Review, \#pagerange\#.

https://doi.org/10.1016/j.ememar.2018 .08 .001

Lee, K. (2017). Systematic exchange rate variation: Where does the dollar factor come from? International Review of Economics and Finance, 56, 288-307. https://doi.org/10.1016/j.iref.2017.10.0 30

Mamadli, S. (2017). Analysis of chaos and nonlinearities in a foreign exchange market. In Procedia Computer Science (Vol. 120, pp. 901-907). Budapest, Hungary: Elsevier B.V. https://doi.org/10.1016/j.procs.2017.11 .324

Moghaddam, A. H., Moghaddam, M. H., \& Esfandyari, M. (2016). Stock market index prediction using artificial neural network. Journal of Economics, Finance and Administrative Science, 21(41), 89-93. https://doi.org/10.1016/j.jefas.2016.07. 002

Nikentari, N., Kurniawan, H., Ritha, N., \& Kurniawan, D. (2018). OPTIMASI JARINGAN SYARAF TIRUAN BACKPROPAGATION DENGAN PARTICLE SWARM OPTIMIZATION UNTUK PREDIKSI PASANG SURUT AIR LAUT. Jurnal Teknologi Informasi Dan IImu Komputer (JTIIK), 5(5). https://doi.org/10.25126/jtiik20185510 55

Pandey, T. N., Jagadev, A., Dehuri, S., \& Cho, S. B. (2018). A novel committee machine and reviews of neural network and statistical models for currency exchange rate prediction: An experimental analysis. Journal of King Saud University - Computer and Information Sciences. https://doi.org/10.1016/j.jksuci.2018.0 2.010

Prasetyoningsih, D., Taunay, E. G. P., \& Fathoni, A. (2018). Pengaruh Nilai Tukar Rupiah Terhadap Return Saham yang Terdaftar di Bursa Efek Indonesia (Studi Kasus Perusahaan LQ 45 Periode Januari 2012 - Desember 2015). Journal Of Management Unpand, 4(4).

Shen, F., Chao, J., \& Zhao, J. (2015). Forecasting exchange rate using deep belief networks and conjugate gradient method. Neurocomputing, 167, 243253.

https://doi.org/10.1016/j.neucom.2015. 04.071

Shu, L., Shi, K., \& Ye, H. (2018). Exchange rate volatility and trade: The role of credit constraints. Review of Economic Dynamics, 30(April), 203-222. https://doi.org/10.1016/j.red.2018.05.0 02

Steinwandter, V., Šišmiš, M., Sagmeister, P., Bodenhofer, U., \& Herwig, C. (2018). Multivariate analytics of chromatographic data: Visual computing based on moving window factor models. Journal of Chromatography B: Analytical Technologies in the Biomedical and Life Sciences, 1092, 179-190. https://doi.org/10.1016/j.jchromb.2018. 06.010 
Sugianto, C. A., \& Fachruddin, F. (2018). Prediksi Pergerakan Harga Valas Menggunakan Algoritma Neural Network. Jurnal Pengembangan IT (JPIT), 03(01), 20-25.

Suryani, N., \& Priyanti, E. (2019). Optimasi Naïve Bayes Dan Algoritma Genetika Untuk Prediksi Penerimaan Beasiswa Pendidikan Pada SMP Utama. Jurnal Teknik Komputer AMIK BSI, V(2), 5158. https://doi.org/10.31294/jtk.v4i2

Thinyane, H., \& Millin, J. (2011). An Investigation into the Use of Intelligent Systems for Currency Trading. Computational Economics, 37(4), 363374. https://doi.org/10.1007/s10614011-9260-4
Wahyuni, I., Ahda, F. A., \& Adipraja, P. F. E. (2018). Penerapan Metode Hybrid Fis Tsukamoto Dan Algoritma Genetika Untuk Prediksi Curah Hujan Di Daerah Batu. Jurnal Teknologi Informasi Dan IImu Komputer (JTIIK), 5(4), 483-492. https://doi.org/10.25126/jtiik.

Wicaksono, S. A. (2019). Optimasi Sistem Penempatan Magang Menerapkan Algoritme Genetika. Jurnal Teknologi Informasi Dan IImu Komputer (JTIIK), 6(1).

https://doi.org/10.25126/jtiik.20196950

Windarti, M., \& Sulistyowati, I. (2019). Korelasi Nilai UN, IP Tahun Pertama Terhadap Masa Studi Dengan Backpropagation. Jurnal IImiah SISFOTENIKA, 9(2), 114-124. 